\title{
Clinical manifestations of COVID-19 in the general population: systematic review
}

\author{
Rodrigo da Rosa Mesquita (D) - Luiz Carlos Francelino Silva Junior (D) - Fernanda Mayara Santos Santana (D) \\ Tatiana Farias de Oliveira (D) - Rafaela Campos Alcântara (D) - Gabriel Monteiro Arnozo (D) Etvaldo Rodrigues da \\ Silva Filho (D) - Aisla Graciele Galdino dos Santos (D) Euclides José Oliveira da Cunha (D) \\ Saulo Henrique Salgueiro de Aquino (D) Carlos Dornels Freire de Souza (D)
}

Received: 6 August 2020 / Accepted: 19 October 2020 / Published online: 26 November 2020 (c) Springer-Verlag GmbH Austria, part of Springer Nature 2020

\begin{abstract}
Summary Clinical manifestations of COVID-19 are varied in the general population. This study aimed to systematize the literature regarding clinical manifestations of patients with confirmed COVID-19. A systematic review of the literature was conducted. A total of 8070 scientific productions were found in the databases. Among the studies, 184 met the initial inclusion criteria, with a total of 114,046 patients. After complete reading, 32 studies that did not report clinical manifestations were excluded. The 152 publications finally included a total of 41,409 individuals from at least 23 countries and 26 different clinical manifestations were reported. In percentage terms, 6 symptoms had a general prevalence greater than or equal to $25 \%$, namely, fever $(58.66 \%)$, cough (54.52\%), dyspnea (30.82\%), malaise $(29.75 \%)$, fatigue $(28.16 \%)$ and sputum/secretion $(25.33 \%)$. Neurological symptoms $(20.82 \%)$, dermatological manifestations $(20.45 \%)$, anorexia (20.26\%), myalgia (16.9\%), sneezing $(14.71 \%)$, sore throat $(14.41 \%)$, rhinitis (14.29\%), goosebumps (13.49\%), headache (12.17\%), chest pain $(11.49 \%)$ and diarrhea $(9.59 \%)$ were other
\end{abstract}

\section{Electronic supplementary material The online version of this article (https://doi.org/10.1007/s00508-020-01760-4) contains supplementary material, which is available to authorized users.}

R. da Rosa Mesquita $\cdot$ L. C. Francelino Silva Junior · F. M. Santos Santana - T. Farias de Oliveira - R. Campos Alcântara · G. Monteiro Arnozo · E. Rodrigues da Silva Filho · A. G. Galdino dos Santos • E. J. Oliveira da Cunha .

S. H. Salgueiro de Aquino · C. D. Freire de Souza ( $\square)$ Department of Medicine, Federal University of Alagoas, Arapiraca, Brazil carlos.freire@arapiraca.ufal.br

\section{D. Freire de Souza}

Campus Arapiraca, Rodovia AL-115, Bom Sucesso, Federal University of Alagoas, 57309-005 Arapiraca, Alagoas, Brazil common symptoms. Only one study reported dermatological manifestations. The least frequent sign/ symptom was hemoptysis (1.65\%). In studies with more than 100 patients, the 3 main symptoms were fever (57.93\%), cough (54.21\%), and dyspnea (30.64\%). Dermatological manifestations do not appear among the main symptoms. The identification of all clinical manifestations of COVID-19 is essential for an early diagnosis and the adoption of preventive measures.

Keywords Coronavirus infection - Epidemiology · SARS virus · General symptoms

\section{Introduction}

In late 2019 the first cases of pneumonia of unknown etiology were identified in Wuhan, Hubei Province, People's Republic of China [1]. Chinese authorities identified a new type of severe acute respiratory syndrome coronavirus 2 (SARS-CoV-2), which rapidly spread across the globe, causing the coronavirus disease 2019 (COVID-19) pandemic [2-4].

On 11 March the World Health Organization (WHO) declared the COVID-19 a pandemic [5]. From the moment of the first cases to 23 September 2020, more than 31 million people were confirmed with the virus, and more than 971,000 deaths have occurred due to the disease [6]. Faced with this rapid spread, researchers are studying the clinical characteristics, means of transmission, and severity in order to promote measures that contribute to disease prevention and better prognosis.

Like SARS-CoV, Middle East respiratory syndrome coronavirus (MERS-CoV), and animal coronaviruses, SARS-Cov-2 infection is not restricted to the respiratory system, but it may trigger an excessive immune response, leading to multiple organ failure and death [7]. Compared to other coronaviruses, the lethality of 
SARS-CoV-2 is lower than that of SARS and MERSrelated diseases, but transmission is easier than other respiratory diseases, which makes COVID-19 more concerning [8].

The first epidemiological studies have showed that the main symptoms of the disease are fever, dry cough, dyspnea, and headache, with progression to pneumonia [9]. With the spread of the disease around the world and the consequent increase in the number of patients, other symptoms began to be reported in scientific investigations.

Awareness of these symptoms can help doctors make the correct initial suspected diagnosis of COVID-19, facilitating the adoption of necessary measures for early clinical management, as well as procedures that reduce the spread of the virus, such as social isolation and/or quarantine. In this respect, this study aimed to systematize the literature regarding the clinical manifestations of patients with confirmed COVID-19.

\section{Methods}

\section{Data sources and search strategies}

This is a systematic review conducted according to the preferred reporting items for systematic reviews and meta-analyzes (PRISMA) [7] recommendations. The research question was: what are the most common clinical manifestations in patients diagnosed with COVID-19?

For the systematic review, we selected studies that address epidemiological characteristics of patients hospitalized with COVID-19 published in PubMed, Medline and Scopus databases between 1 January and 24 April 2020, using the descriptors COVID-19, SARS-CoV-2, 2019-nCoV, n-CoV and coronavirus combined with "clinical profile" or "epidemiological profile". We sought to identify the clinical manifestations that were prevalent in studies of patients diagnosed with COVID-19. For the search strategy, the Boolean operators "AND" and "OR" were applied. In addition, a manual search was carried out for references cited in the articles.

\section{Research variables}

In this study, we sought to identify characteristics about clinical manifestations in patients with COVID19. The following variables were researched: country of study, study population, sex (male and female), age and clinical manifestations.

\section{Eligibility criteria}

Clinical trials, cohorts, cross-sectional, clinical cases and case series studies (published and preprint), published in any language, were included. Government epidemiological bulletins, comments, literature reviews, articles without full access to content and studies in animals were excluded.

\section{Selection of studies}

The search was carried out by four independent researchers. After this step, three researchers independently performed the following steps: 1) reading the title and summary to identify potential eligible studies; 2) reading the full text; 3) collection of variables and assembly of the database. The divergences were

Fig. 1 Study selection flowchart. 2020
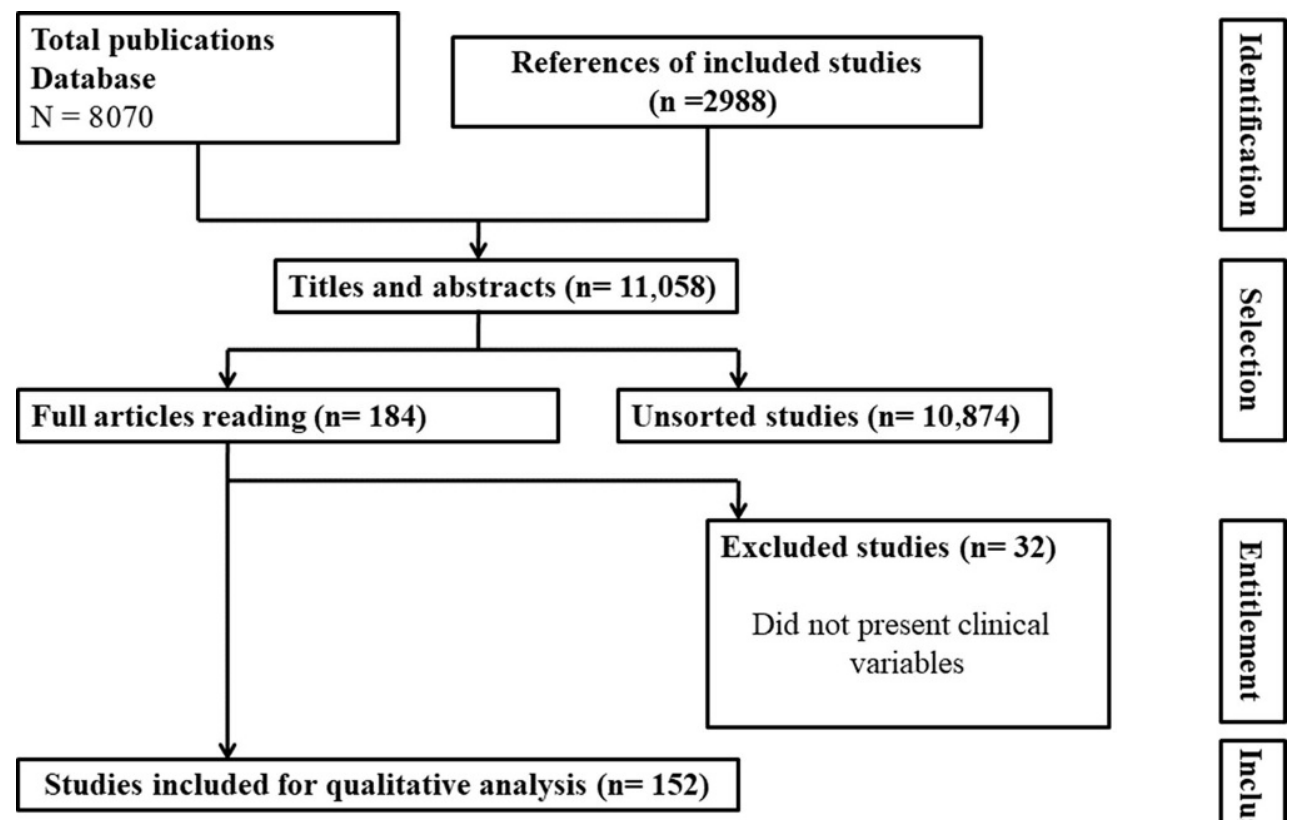
analyzed and resolved by consensus between the researchers.

\section{Data extraction}

For data extraction, the researchers created a database. The data was entered by a first investigator and subsequently checked by a second investigator on the team. The systematization/analysis of the data was conducted by two other independent researchers.

\section{Results}

Initially, 8070 scientific productions were found in the databases, 184 of which met the initial inclusion criteria, with a total of 114,046 patients. After full reading, 32 scientific productions that did not report clinical manifestations were excluded (Fig. 1). The remaining 152 publications totalled a population of 41,409 (Supplement 1) individuals from the following 23 countries: Germany, Bolivia, Brazil, China, Korea, South Korea, Spain, USA, France, United Kingdom, India, Iceland, Italy, Poland, Singapore, Thailand, Belgium, Finland, Russia, Japan, Pakistan, Philippines and Sweden. The following three analyses were conducted: first, all studies were considered; second, only studies with 10 or more individuals were considered, and third, only studies with a population equal to or greater than 100 individuals were considered.

Regarding gender, $52.27 \%(n=21,594)$ were men and $47.73 \%(n=19,715)$ women, reported in 151 studies. The mean age of the patients was 46.20 years (145 studies). 2 studies took place in neonates, 13 in children, 6 in pregnant women, 3 in the older and 121 in the general population. Asymptomatic patients were reported in 133 studies, representing $2.27 \%$ of patients. A total of $3467(8.54 \%)$ deaths occurred (Table 1).

Table 1 Characterization of the included studies

\begin{tabular}{|c|c|c|c|c|}
\hline & \multirow{2}{*}{$\begin{array}{l}\text { Studies }^{\mathrm{a}} \\
(n)\end{array}$} & \multirow{2}{*}{$\begin{array}{l}\text { Median age } \\
\text { (years) }\end{array}$} & \multicolumn{2}{|l|}{ Total } \\
\hline & & & $n$ & $\%$ \\
\hline Total & 145 & 46.2 & A & A \\
\hline \multicolumn{5}{|l|}{ Gender } \\
\hline Male & 151 & A & 21,594 & 52.27 \\
\hline Female & 151 & A & 19,715 & 47.73 \\
\hline \multicolumn{5}{|l|}{ Population } \\
\hline Newborns & 2 & 19.63 days & 14 & 0.03 \\
\hline Children & 13 & 6.88 & 236 & 0.57 \\
\hline Pregnant women & 6 & 33.14 & 93 & 0.22 \\
\hline Seniors & 3 & 72.56 & 365 & 0.88 \\
\hline General & 121 & 51.19 & 39,114 & 94.46 \\
\hline Asymptomatic & 133 & A & 651 & 2.27 \\
\hline Deaths & 141 & A & 3467 & 8.54 \\
\hline
\end{tabular}

At least 26 different clinical manifestations have been reported in the articles. The most reported ones were: fever (144 studies), cough (139 studies), dyspnea (99 studies), diarrhea (85 studies), fatigue (78 studies), headache (76 studies) and myalgia (69 studies). In percentage terms, six symptoms had a general prevalence greater than $25 \%$, considering studies that reported specific clinical manifestations: fever (58.66\%), cough $(54.52 \%)$, dyspnea (30.82\%), malaise $(29.75 \%)$, fatigue $(28.16 \%)$, and sputum/secretion (25.33\%). Neurological symptoms (20.82\%), dermatological manifestations $(20.45 \%)$, anorexia $(20.26 \%)$, myalgia $(16.9 \%)$, sneezing $(14.71 \%)$, sore throat $(14.41 \%)$, rhinitis (14.29\%), goosebumps (13.49\%), headache $(12.17 \%)$, chest pain $(11.49 \%)$ and diarrhea $(9.59 \%)$ were other frequent symptoms. It is necessary to highlight that only one study reported dermatological manifestations. Hemoptysis $(1.65 \%)$ was the least frequent clinical manifestation. There was also a considerable variation in the frequency of symptoms between studies. In studies with more than 100 patients, the 3 main symptoms were fever (57.93\%), cough $(54.21 \%)$, and dyspnea $(30.64 \%)$. Furthermore, dermatological manifestations were not among the main symptoms reported in studies with more than 100 individuals.

\section{Discussion}

COVID-19 patients may have a wide range of clinical manifestations. This analysis managed to identify at least 26 of these manifestations, although this effort is still far from representing a final list of symptoms. It is necessary to highlight the illustrative number of presentations, given that generic terms such as neurological and dermatological manifestations imply a range of specific responses, which could substantially increase numbers of signs and symptoms.

Regarding SARS-CoV-2, in general, these findings are nonspecific, such as dyspnea, fever, cough, and headache. The severity of the infection may vary from asymptomatic patients to severe cases of pneumonia that can lead to death [9-11]. Initially, the disease was characterized by the triad fever, cough, and shortness of breath. The US Center for Disease Control and Prevention (CDC) subsequently added chills, muscle pain, headache, sore throat, and loss of taste or smell to this list (neurological manifestations) [12].

Fever was the most common finding observed among patients (58.66\%), which signals the organism's response to toxic substances that affect temperature regulating centers [13]. This symptom can appear throughout the course of various infectious diseases, and, although it is a beneficial signaling process for the host, it demands a considerable increase in energy metabolism [14]. When compared to diseases caused by other members of the coronavirus family, such as SARS-CoV (99\%) and MERS-CoV (98\%), studies suggest that fever is less frequent in COVID-19 [15]. 


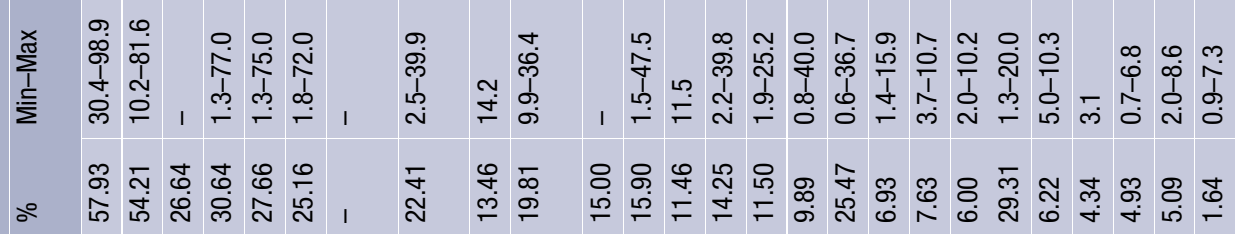

을 :

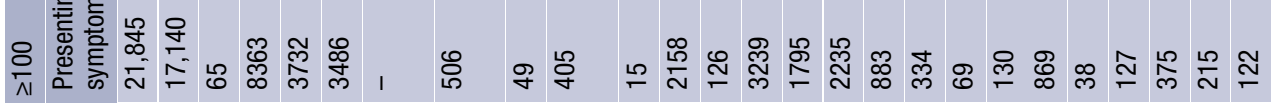
일

苋

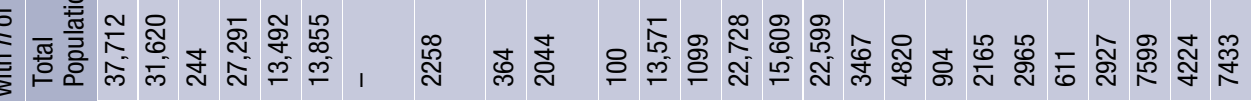
产

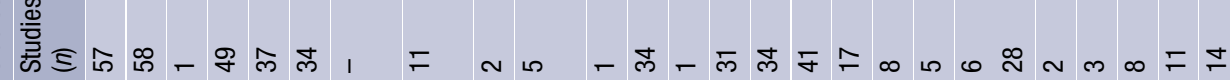

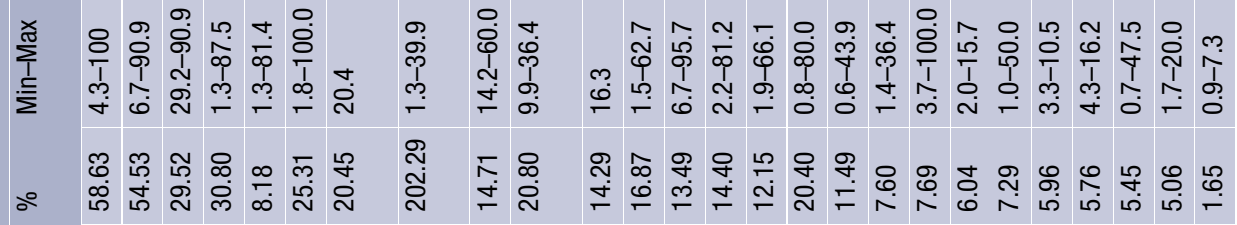

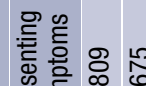

신

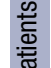

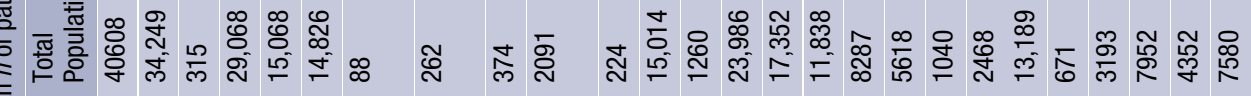
录

융

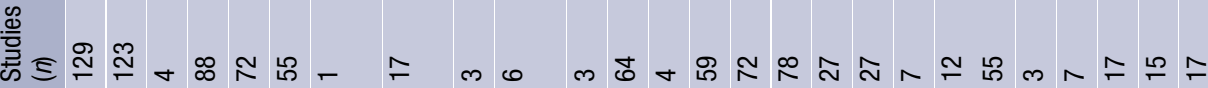

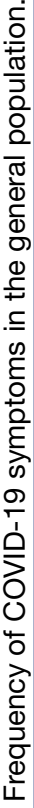

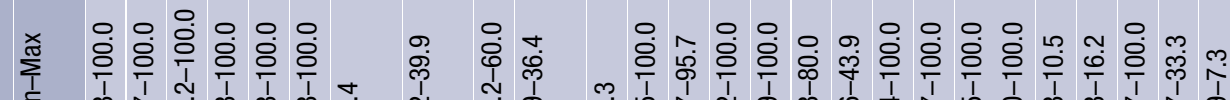

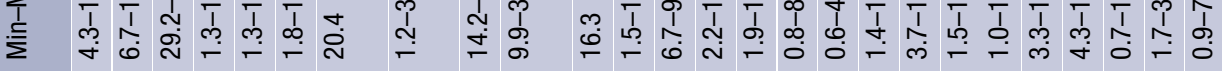
๕ ๑ 舟

율

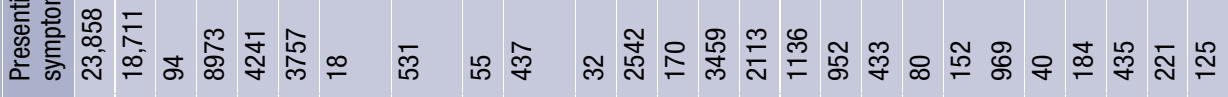
음 등

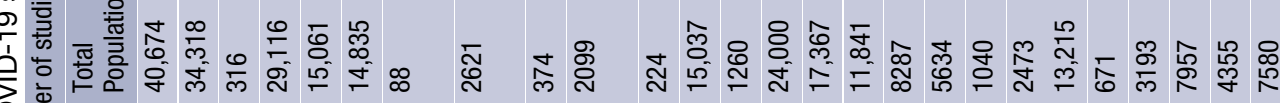

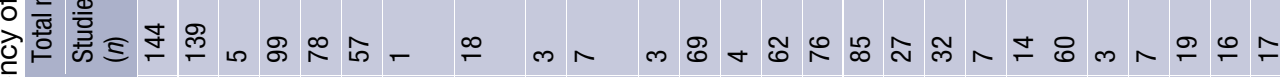

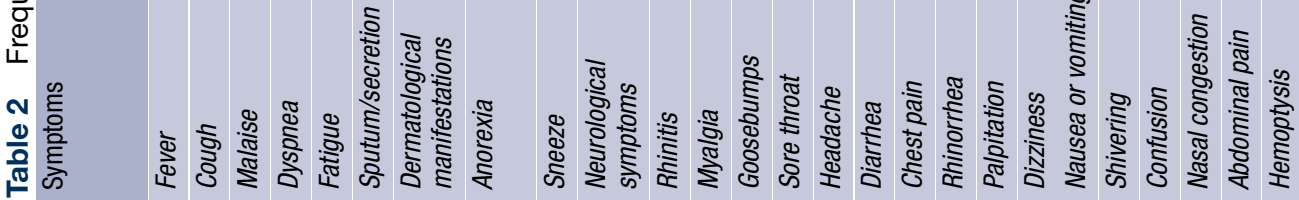


Cough was the second most common manifestation $(54.52 \%)$, and it is directly linked to the transmission of the virus through respiratory droplets [16]. The cough reflex improves release of secretions and particles from airways as a result of irritating mechanisms, such as accumulated secretions, postnasal drip, and pathogens, in addition to inflammatory processes. In some conditions, it can become excessive and potentially harmful to the airway mucosa [17]. Additional symptoms associated with the upper respiratory tract have also been observed, such as sneezing, nasal congestion, and sore throat.

Dyspnea was seen in $30.82 \%$ of the reported patients, and it is generally related to greater severity of the condition. During physical examination, patients in serious condition present, in addition to dyspnea, increased respiratory rate, speech tremor, weakened breath sounds, and dullness on lung percussion [10, 16]. Most of these severe patients had comorbidities, such as cardiovascular disorders, hypertension, and diabetes [10, 11, 18]. Additionally, radiological findings of these patients showed ground-glass opacities and consolidation, especially in the periphery of the lungs. When these conditions were present, there was an increase in mortality [10, 16, 19].

Fatigue is widely reported in several studies, which places it among the most significant occurrences of the disease $[10,11,15,19]$. This symptom may be related to the increase in viral load and to the immune response to the infectious process [19]. In addition, insufficient energy production to meet the required metabolic demands relates fatigue to other symptoms, such as dyspnea and myalgia [20].

Neurological symptoms $(20.82 \%)$ are also among the most common clinical manifestations. The neuroinvasive potential of the virus could influence the development of respiratory failure in some individuals, in addition to contributing to the anosmia/ hyposmia and dysgeusia reported by some patients [19]. Neurotropism and its repercussions are still poorly understood [19]. Although not very detailed in the studies, anosmia and hyposmia are already proposed as possible initial manifestations of the disease, especially in paucisymptomatic patients, in addition to being relevant for the differential diagnosis of SARSCoV-2 infection [21-23].

Dermatological symptoms have recently been associated with COVID-19, including nonspecific manifestations, such as erythematous rash and generalized urticaria as well as more specific characteristics, such as chickenpox rash [24, 25]. Acral ischemia has also been described in patients with severe forms of COVID-19, such as cyanosis of toes, skin blisters, and dry gangrene [26, 27].

Regarding less prevalent symptoms, although reported in 16 studies, hemoptysis was observed in only $1.64 \%$ of patients. This clinical finding reflects the severity of the disease in a proportion of hospitalized patients, with high risk of death $[10,15,16,20]$.
As it presents with diverse clinical manifestations, which are in most cases similar to other respiratory diseases, it is difficult to differentiate COVID-19 during the initial phase [19]. There is no pathognomonic sign/symptom as seen in other viral diseases, such as measles and chickenpox, for example. In addition, it is necessary to highlight that the initial manifestations may vary significantly from one patient to another, characterizing COVID-19 as a clinically dynamic disease.

On the other hand, the present study showed a small number of asymptomatic patients $(n=651$; $2.27 \%$ ). This group is composed mainly of young people and women without coexisting diseases, who do not have a significant increase in C-reactive protein (CRP) and do not frequently present radiological findings. [28-30]. Despite the low percentage, asymptomatic cases represent a difficult scenario to control, even in the presence of a single unidentified case, since the virus is easily spread by contaminated droplets and the transmissibility of this patient seems to be equivalent to the symptomatic patient [31, 32]. Thus, given the difficulty of screening, social distancing remains a crucial recommendation to slow the spread of the virus.

Additionally, further studies should be conducted with the aim of identifying the most prevalent symptoms in different population groups (children, older people, and pregnant women, for example), in different contexts (community and hospital) as well as levels of severity. This information is essential to define risk estimates of worse outcomes. Finally, knowledge of all possible symptoms in patients with COVID-19 can facilitate early diagnosis and the adoption of measures necessary to contain the transmission chain in the community.

Author contributions Mesquita RR, Freire de Souza CD, Francelino Silva Junior LC, Santana FMS, Oliveira TF, Alcântara RF, Arnozo GM, Silva Filho ER, Santos AGG, Oliveira da Cunha EJ, Aquino SHS designed the study, independently collected and analyzed the data, interpretation of the data. Drs Souza CDF and Mesquita RR revised it critically for important intellectual content. All authors agreed to be accountable for all aspects of the work and approved the final version of the paper.

Funding This study did not receive funding from any financial source.

Conflict of interest R. da Rosa Mesquita, L.C. Francelino Silva Junior, F.M. Santos Santana, T. Farias de Oliveira, R. Campos Alcântara, G. Monteiro Arnozo, E. Rodrigues da Silva Filho, A.G. Galdino dos Santos, E.J. Oliveira da Cunha, S.H. Salgueiro de Aquino, and C.D. Freire de Souza declare that they have no competing interests.

\section{References}

1. World Health Organization. Pneumonia of unknown cause-China. 2020. https://www.who.int/csr/don/05- 
january-2020-pneumonia- of-unkown-cause-china/en/. Accessed 16 May 2020.

2. World Health Organization. Novel Coronavirus-China. 2020. https://www.who.int/csr/don/12-january-2020novel-coronavirus-china/en/. Accessed 16 May 2020.

3. Burke RM, Midgley CM, Dratch A, et al. Active monitoring of persons exposed to patients with confirmed COVID19-United States, january-february 2020. MMWR Morb Mortal Wkly Rep. 2020;69(9):1-2. https://www.cdc.gov/ $\mathrm{mmwr} /$ volumes/69/wr/pdfs/mm6909el-H.pdf.

4. Zhu N, Zhang D, Wang W, Li X, Yang B, Song J, et al. A novel coronavirus from patients with pneumonia in China, 2019. NEngl J Med. 2020;382(8):1-7. https:/ / www.nejm.org/doi/ full/10.1056/NEJMoa2001017.

5. World Health Organization. Coronavirus disease (COVID19) Pandemic. 2020. https://www.who.int/emergencies/ diseases/novel-coronavirus-2019. Accessed21 May 2020.

6. University JH. Coronavirus resource center. 2020. https:// coronavirus.jhu.edu/map.html. Accessed Internet.

7. Cyranoski D. Profile of a killer: the complex biology powering the coronavirus pandemic. Nature. 2020;581:1-5. https://media.nature.com/original/magazine-assets/d41 586-020-01315-7/d41586-020-01315-7.pdf.

8. Callaway E, Cyranoski D, Mallapaty S, Stoye E, Tollefson J. The coronavirus pandemic in five powerful charts. Nature. 2020;579:1-2. https://media.nature.com/ original/magazine-assets/d41586-020-00758-2/d41586020-00758-2.pdf.

9. Zhou P, Yang XL, Wang XG, Hu B, Zhang L, Zhang W, et al. A pneumonia outbreak associated with a new coronavirus of probable bat origin. Nature. 2020;579(7798):1-4. https:// www.ncbi.nlm.nih.gov/pmc/articles/PMC7095418/.

10. Wu D, Wu T, Liu Q, Yang Z. The SARS-CoV-2 outbreak: what we know. Int J Infect Dis. 2020. https://www.ncbi.nlm.nih. gov/pmc/articles/PMC7102543/pdf/main.pdf. Accessed 28 May 2020.

11. Tu H, Tu S, Gao S, Shao A, Sheng J. The epidemiological and clinical features of COVID-19 and lessons from this global infectious public health event. J Infect. 2020. https://doi. org/10.1016/j.jinf.2020.04.011.

12. Center for Disease Control and Prevention. Coronavirus disease 2019 (COVID-19). https://www.cdc.gov/ coronavirus/2019-ncov/symptoms-testing/symptoms. html. Accessed 27 May2020.

13. Hall JE. Guyton y Hall. Tratado de fisiología médica. 12th ed. Rio de Janeiro: Elsevier; 2011.

14. Plaza JJG, Hulak N, Zhumadilov Z, Akilzhanova A. Fever as an important resource for infectious diseases research. Intractable Rare Dis Res. 2016;5(2):1-6. https://www. ncbi.nlm.nih.gov/pmc/articles/PMC4869589/pdf/irdr-597.pdf.

15. Guan W, Ni Z, Hu Y, Liang W, Ou C, He J, et al. Clinical characteristics of coronavirus disease 2019 in China. NEngl J Med. 2020;382(18):1708-20. https://www.nejm.org/doi/ pdf/10.1056/NEJMoa2002032?articleTools=true.

16. Mungroo MR, Khan NA, Siddiqui R. Novel Coronavirus: current understanding of clinical features, diagnosis, pathogenesis, and treatment options. Pathogens. 2020;9(4):297. https://www.mdpi.com/2076-0817/9/4/297/htm.

17. Polverino M, Polverino F, Fasolino M, Andò F, Alfieri A, De Blasio F. Anatomy and neuro-pathophysiology of the cough reflex arc. Multidiscip Respir Med. 2012;7(1):1-5. https://dash.harvard.edu/bitstream/ handle/1/10468020/3415124.pdf?sequence $=1$ \&is Allowed $=\mathrm{y}$.
18. Liu K, Chen Y, Lin R, Han K. Clinical features of COVID19 in elderly patients: a comparison with young and middle-aged patients. J Infect. 2020. https://doi.org/10. 1016/j.jinf.2020.03.005. https://www.ncbi.nlm.nih.gov/ pmc/articles/PMC7102640/pdf/main.pdf.

19. Brann DH, Tsukahara T, Weinreb C, Logan DW, Datta SR. Non-neural expression ofSARS-CoV-2 entrygenes in the olfactory epithelium suggests mechanisms underlying anosmia in COVID-19 patients. bioRxiv. 2020. https://doi.org/ 10.1101/2020.03.25.009084.

20. Woo K. A pilot study to examine the relationships of dyspnoea, physical activity and fatigue in patients with chronic obstructive pulmonary disease. J Clin Nurs. 2000;9(4):1-8. https://doi.org/10.1046/j.1365-2702.2000.00361.x.

21. Vaira LA, Salzano G, Deiana G, De Riu G. Anosmia and Ageusia: commonfindingsinCOVID-19 patients. Laryngoscope. 2020; https://doi.org/10.1002/lary.28692.

22. Joffily L, et al. The close relationship between sudden loss of smell and COVID-19. Braz J Otorhinolaryngol. 2020. https://doi.org/10.1016/j.bjorl.2020.05.002.

23. Pascarella G, Strumia A, Piliego C, Bruno F, Del Buono R, Costa $\mathrm{F}$, et al. COVID-19 diagnosis and management: a comprehensive review. J Intern Med. 2020; https://doi. org/10.1111/joim.13091.

24. Recalcati S. Cutaneous manifestations in COVID-19: a first perspective. J Eur Acad Dermatol Venereol. 2020; https:// doi.org/10.1111/jdv.16387.

25. Marzano AV, Genovese G, Fabbrocini G, et al. Varicellalike exanthem as a specific COVID83 19-associated skin manifestation: multicenter case series of 22 patients. J Am Acad Dermatol. 2020. https://doi.org/10.1016/ j.jaad.2020.04.044. https://www.ncbi.nlm.nih.gov/pmc/ articles/PMC7161488/pdf/main.pdf.

26. Zhang Y, Cao W, Xiao M, Li YJ, Yang Y, Zhao J, et al. Clinical and coagulation characteristics of 7 patients with critical COVID-2019 pneumonia and acro-ischemia. Zhonghua Xue Ye Xue Za Zhi. 2020;41:1-9. http://rs.yiigle.com/ yufabiao/1186612.htm.

27. Fernandez-Nieto D, Jimenez-Cauhe J, Suarez-Valle A, Moreno-Arrones OM, Saceda-Corralo D, Arana-Raja A, etal. Characterization of acute acro-ischemic lesions in nonhospitalized patients: a case series of 132 patients during the COVID-19 outbreak. J Am Acad Dermatol. 2020. https://doi.org/10.1016/j.jaad.2020.04.093. https://www. ncbi.nlm.nih.gov/pmc/articles/PMC7195051/pdf/main. pdf.

28. $\mathrm{Xu} \mathrm{X-W}$, et al. Clinical findings in a group of patients infected with the 2019 novel coronavirus (SARS-Cov-2) outside of Wuhan, China: retrospective case series. BMJ. 2020;368:m606.

29. Guan W-J, et al. Clinical characteristics of Coronavirus disease 2019 in China. N Engl J Med. 2020. https://doi.org/ 10.1056/NEJMoa2002032.

30. Dai W, et al. Clinical characteristics of asymptomatic patients with SARS-coV-2 in Zhejiang: an imperceptible source of infection. Can Respir J. 2020; https://doi.org/10. $1155 / 2020 / 2045341$.

31. Shao S, et al. Risk assessment of airborne transmission of COVID-19 by asymptomatic individuals under different practical settings. JAerosol Sci. 2021;151:105661.

32. Kinoshita R, et al. Containment, contact tracing and asymptomatic transmission of novel Coronavirus disease (COVID-19): a modelling study. JClin Med. 2020;9:3125.

Publisher's Note Springer Nature remains neutral with regard to jurisdictional claims in published maps and institutional affiliations. 